\title{
Tensions and paradoxes in health involving rights, knowledge and trust: mapping the debate and pointing to directions of research
}

Rights, knowledge and trust are key drivers of comprehensive-based health systems around the globe regardless of specific functioning and funding schemes. Health-related rights build around the expectancy of living longer and better on the basis of an inclusive definition of health that embraces well-being and in which access to healthcare and respect for individuals' self-determination are two cornerstones. Health-related knowledge regards the role of evidence in clinical and political decision-making and, increasingly, articulation with better informed, more demanding lay knowledge. Trust in health entails individuals' relationship with health systems and professionals. Underpinning this relationship is a moral contract based on which individuals partially abdicate personal choices and motivations in favour of collective management of knowledge and behaviours. The outcome is presumably the pursuit of equal opportunities and less exposure to the market's negative effects.

Much has been said about the positive effects of representative policies, respect for the different types of knowledge and the collective risk management on health outcomes and social cohesion. Also, the multiplying effect of comprehensive-based health systems on the economy and social security schemes is still undeniable in so-called post-truth politics.

The political pathway on health issues in both developing and developed countries in the second half of the $20^{\text {th }}$ century was able to overcome wellknown tensions. Policies have been increasingly aligned with the needs of migrants, ethnic and religious minorities, women, children, the elderly and LGBTI. Regulators have sought to interfere more and more in professionals' conduct to ensure safe, transparent clinical decisions and ensure better control over the provision of healthcare. Knowledge has been given a key position in informing policy decision-making and protecting people's lives. The people's voice has been heard more and more in the governance of health systems.

The issue in 2020 should be whether these past tensions have been effectively overcome and the extent to which new paradoxes are making the unsolved problems more complex.

Where old tensions are concerned, health inequalities persist and healthrelated rights are not always respected. Health professionals' conduct is under continuous scrutiny even though their mediating role between evidence and users is perceived as decisive to population health, which has resulted in a seemingly contradictory relationship of distrust of and dependence on expert knowledge. Users are held accountable for their choices while the constraints underpinning individual lifestyles are ignored. Private for-profit investment in $R \& D$ is still just as important to ground-breaking knowledge and technologies, because it conditions political and academic agenda-setting, even though it builds on unfair geopolitical relationships around the world due to complex links involving health in political, military and economic affairs.

Emerging paradoxes in health include global warming, the 2008 financial and economic crisis, the growing flows of migrants and refugees, the resurgence of political extremism and nationalism, just to mention a few examples. These phenomena are not geographically delimited and they impact on a considerable number of people. They affect people's health and well-being and the functioning of health systems on a global scale and call for further academic attention.

'Old Tensions, Emerging Paradoxes in Health: rights, knowledge, and trust' set the tone for the $17^{\text {th }}$ European Society for Health and Medical Sociology 
biennial conference held in Portugal in 2018. The main topics of discussion at the conference are summarized here for a diagnosis of some health-related tensions and paradoxes around the globe and point to directions for future research.

Medicalization (the way 'things are made medical') is still key in the debate and is embraced in multidimensional approaches. One approach to medicalization has to do with the ethical and moral issues of biotechnological innovation, given that its practices and decisions may change individuals' expectations of their living experience and relationships with others, especially in transitional stages of life (e.g. medically assisted procreation and palliative care ${ }^{1}$ ). Another approach to medicalization concerns disputes for rights and legitimacy. The extent to which medical doctors seek to protect the status of medicine's scientific evidence and allied health professionals to demonstrate the value of their practice is wellknown. Furthermore, the different branches of so-called complementary and alternative medicine are shining the light on the added value of non-biomedical approaches to life. An emerging issue is how individuals and groups make use of medical knowledge against specific views of the interplay between pathology and behaviours (e.g. the transition stories of trans-men and their views of masculinity ${ }^{2}$ ). The point is whether medicalization and pathologisation are distinct analytical dimensions, in which it is helpful to bring concepts like agency and reflexivity to the debate. Briefly, the underlying issue in studying medicalization should be make better sense of empirical differences as to how diseases and pathologies are acknowledged as such in the global context of medical pluralism ${ }^{3}$.

Human reproduction is not a new topic, although it is too often disregarded outside feminist studies and social movements. Greater importance needs to be given to the intersection between forms of social and political regulation and individuals' rights to self-determination in order to strengthen academic research. One question is whether these forces are in opposition or somehow articulate and, in the latter case, how the articulation translates. Another question is how the dimensions involved in human reproduction (e.g. fertility, contraceptive choices, assisted reproductive technologies, childbirth and parenting roles) are linked to a variety of analytical dimensions. These include bodily experiences, gender representations, social stratification, migration, work models, work-family balance, the interplay between lay experiences and expert knowledge, healthcare funding and delivery, professional practices, ideologies and values and agency and citizenship rights ${ }^{4-6}$.

Knowledge and trust in health are interrelated topics about which there is a vast array of literature. Trust has to do with the truster's positive expectations from the trustee's expertise and intentions. Traditionally viewed from users' and regulators' perspectives of health professionals, it has been increasingly argued that there should be more evidence on professionals' trust in their peers, healthcare providers, funders, scientific evidence and patients. Also, we need to know whether and how technology shapes trustworthiness ${ }^{7}$. Another topic of discussion is whether trust in the medical profession is in decline, as empirical evidence points to seemingly contradictory findings in different countries and health services ${ }^{8}$. What may be at stake are different regulatory processes that in fact change normative conceptions of trust, although empirical misinterpretations should not be ruled out. One step towards better identification of empirical misinterpretation as to whether trust in the medical profession is in decline is to pinpoint the focus of scepticism. Does it relate to the knowledge itself or to the interacting players? One thing is being sceptical about medical evidence in favour of another type of knowledge; another is being sceptical about who applies the knowledge. The answer to this question entails recognising the disputes 
between lay and expert knowledge and between the different branches of expert knowledge over rights and legitimacy. A third topic of discussion is changes in the clinical approach to evidence, practice and patients that is emerging from within the medical field, so-called narrative medicine. Although academic attention has grown ${ }^{9}$, uncertainties remain as to its content, practice, outcomes and epistemological positioning within the field of medical humanities, hence suggesting the need for further questioning and critical evaluation ${ }^{10}$.

Social inequalities are key in health research and can be explored in the bidirectional link between asymmetric relationships and distribution of resources on the one hand and health, well-being, mortality and morbidity on the other. Initially limited to income-based stratification, conceptual advances have demonstrated that privileges and disadvantages are multidimensional and interdependent ${ }^{11}$. They may be related to cultural and social capitals ${ }^{12-14}$, working conditions, workload and work-family balance ${ }^{15}$, employment status ${ }^{16}$ or gender, ethnicity and citizenship ${ }^{17}$. Moreover, these social inequalities in health systems can be viewed in terms of access to healthcare, quality of user-professional interaction and individuals' ability to understand, cope with and make use of expert information. One interesting direction of research is to expand on the multidimensionality and interdependency of factors underpinning asymmetric relationships and distribution of resources in health. Another is to reflect on how and why certain social attributes in health are linked to dominance and discrimination. A third direction is to look deeper into the twofold influence of social determinants and health outcomes. A fourth direction is to make use of these conceptual developments in applied research, especially epidemiology and related medical fields.

Health reforms are a broad field of discussion that can be approached from different angles of analysis. One angle that was addressed at the conference was the role of clinical leaders in improving cost control, quality and safety as an alternative to top-down decisions from outside health organizations and severe budget cuts ${ }^{18}$. Nonetheless, differences in national health systems and contradictory findings in the literature as to the outcomes of institutional entrepreneurs make it necessary to conduct further empirical research in different countries and settings. Another direction is finding out which actors are best in leadership roles and what combination of professional-managerial expertise best enhances organizational outcomes and intra- and inter-professional relationships. It is also important to study the effects of leadership roles on professions' ideologies, autonomy and authority ${ }^{19}$. Another angle of analysis on health reforms was the adaption of health systems to forced mobility (e.g. migrants, refugees and asylum seekers). This issue has been particularly important in Europe ${ }^{20}$ but it should concern every health system whose principles lie in solidarity and risksharing. The directions of research include how different countries are generally coping with these phenomena, limits to inclusiveness and a rise in discrimination and the political, ideological and representational effects on both the resident population and newcomers ${ }^{21}$. A third angle of analysis of health reforms was users' involvement in decision-making. Studies should foster an analytical position (instead of a normative one) that allows a better understanding of changes in political representativeness and citizenship, individuals' relationships with expert knowledge and institutions and inner dynamics of advocacy groups ${ }^{22}$.

Behaviours, well-being and technologies reflect the effects of seemingly new opportunities given to individuals in the context of consumerism, freedom of choice and informed decisions. One direction of research is how individuals' choices of and accountability for health outcomes link with risk, gender, age, 
equality and emancipation ${ }^{23-25}$. There are also the changes in policies on informal care, self-management and body governance in the pursuit of well-being ${ }^{26}$ and better management of non-communicable and communicable diseases ${ }^{27,28}$. Technology is key to this debate, given that it dematerializes processes, reduces time and space and, by giving individuals room for manoeuvre to make their own decisions, is likely to reconfigure human interactions between users and professionals $\mathrm{s}^{29-31}$. It is also important to further analyse the effects of data privacy and surveillance, and the changes made by artificial intelligence.

Tiago Correia ${ }^{(a)}$

(a) ISCTE - Instituto Universitário de Lisboa. Avenida das Forças Armadas, 1649-026. Lisboa, Portugal. tiago.correia@iscte-iul.pt

\section{References}

1. Delaunay C, Martins AC. Dialectical tensions between caregivers and patients in ART and Palliative Care: ethical and moral issues raised by the (bio)medicalization of birth and death. In: Resende JM, Martins AC, organizers. The making of the common in social relations. Newcastle upon Tyne: Cambridge Scholars Publishing; 2015. p. 53-100.

2. Aboim S, Vasconcelos P. Sexualities in the social world. In: Proceedings of 110th ASA Annual Meeting; 2015; Chicago. Chicago: ASA; 2015.

3. Correia T. Revisiting medicalization: a critique of the assumptions of what counts as medical knowledge. Front Sociol. 2017; 2:14.

4. Borozdina E. Introducing 'natural' childbirth in Russian hospitals. Midwives' institutional work. In: Zvonareva O, Popova E, Horstman K, editors. Health, technologies, and politics in post-soviet settings. Basingstoke: Palgrave Macmillan; 2018. p. 145-71

5. Jette $A C$, Santos $M$. Capturing the complexity of practice as an insider: in-labour ethnography. In: Church S, Frith L, Balaam M-C, Berg M, Smith V, van der Walt $C$, et al. editors. New thinking on improving maternity care: international perspectives. London: Printer and Martin; 2017. p. 73-89.

6. Vanderlinden K, Levecque K, Van Rossem R. Breastfeeding or bottled milk? Poverty and feeding choices in the native and immigrant population in Belgium. J Immigr Minor Health. 2015; 17(2):319-24.

7. Douglass T, Calnan M. Trust matters for doctors? Towards an agenda for research. Soc Theory Health. 2016; 14(4):393-413.

8. Calnan M, Rowe R. Trust matters in healthcare. London: Open University Press; 2008. 
9. Fernandes I, Martins C, Reis A, Sanches Z, editors. Creative dialogues: narrative and medicine. Newcastle upon Tyne: Cambridge Scholars Publishing; 2015.

10. Fernandes I. Leituras holísticas: de Tchékhov à medicina narrativa. Interface (Botucatu). 2015; 19(52):71-82.

11. Gkiouleka A, Huijts T, Beckfield J, Bambra C. Understanding the micro and macro politics of health: inequalities, intersectionality \& institutions-a research agenda. Soc Sci Med. 2018; 200:92-8.

12. Veenstra G. Social capital, SES and health: an individual-level analysis. Soc Sci Med. 2000; 50(5):619-29.

13. Delaruelle $K$, Buffel $V$, Bracke P. Educational expansion and the education gradient in health: a hierarchical age-period-cohort analysis. Soc Sci Med. 2015; 145:79-88.

14. De Clercq B, Abel T, Moor I, Elgar FJ, Lievens J, Sioen I, et al. Social inequality in adolescents' healthy food intake: the interplay between economic, social and cultural capital. Eur J Public Health. 2017; 27(2):279-86.

15. Muckenhuber J, Volk H. Gesundheitliche Ungleichheit im internationalen Vergleich. In: Jungbauer-Gans M, Kriwy P, editors. Handbuch Gesundheitssoziologie. Springer Reference Sozialwissenschaften. Wiesbaden: Springer Fachmedien; 2018. p. 1-27.

16. Mikucka M. Does individualistic culture lower the well-being of the unemployed? Evidence from Europe. J Happiness Stud. 2014; 15(3):673-91.

17. Parra-Casado D, Stornes P, Solheim E. Self-rated health and wellbeing among the working-age immigrant population in Western Europe: findings from the European social survey (2014) special module on the social determinants of health. Eur J Public Health. 2017; 27 Suppl 1:40-6.

18. Denis J-L, Dompierre G, Langley A, Rouleau L. Escalating indecision: between reification and strategic ambiguity. Organ Sci. 2011; 22(1):225-44.

19. Correia T, Denis J-L. Hybrid management, organizational configuration, and medical professionalism: evidence from the establishment of a clinical directorate in Portugal. BMC Health Serv Res. 2016; 16 Suppl 2:161.

20. Botrugno C. Immigrazione ed unione europea: un excursus storico ragionato. Sociol Diritto. 2014; 1:121-43.

21. Lombardi L. Violence against refugee and migrant women. The reproduction of gender discrimination and inequality. Milan: ISMU Foundation; 2017.

22. Raz A, Jordan I, Schicktanz S. Exploring the positions of German and Israeli patient organizations in the bioethical context of end-of-life policies. Health Care Anal. 2014; 22(2):143-59.

23. Følling IS, Solbjør M, Midthjell K, Kulseng BE, Helvik A-S. Exploring lifestyle and risk in preventing type 2 diabetes-a nested qualitative study of older participants in a lifestyle intervention program (VEND-RISK). BMC Public Health. 2016; 16:876.

24. Lewis S, Willis K, Collyer F. Navigating and making choices about healthcare: the role of place. Health Place. 2018; 52:215-20.

25. Verbakel E. How to understand informal caregiving patterns in Europe? The role of formal long-term care provisions and family care norms. Scand J Public Health. 2018; 46(4):436-47.

26. Bloy G, Philippon L, Rigal L. Les médecins généralistes et le conseil en activité physique: des évidences aux contingences de la consultation. Sante Publique. 2016; s1(HS):153-61.

27. Dziuban A, Sekuler T. Mapping HIV-related figures of risk in Europe's blood donation regime. Disentangling European HIV/AIDS policies: activism, citizenship and health (EUROPACH). Working Paper. 2017;17. 
28. Franklin M, Lewis S, Willis K, Bourke-Taylor H, Smith L. Patients' and healthcare professionals' perceptions of self-management support interactions: systematic review and qualitative synthesis. Chronic IIIn. 2018; 14(2):79-103.

29. Maturo A. Doing things with numbers. The quantified self and the gamification of health. J Med Humanit Soc Stud Sci Technol. 2015; 7(1):87-105.

30. Lombi L, Marzulli M, editors. Theorizing sociology in the digital society. Milan: FrancoAngeli; 2017.

31. Petrič G, Atanasova S, Kamin T. Impact of social processes in online health communities on patient empowerment in relationship with the physician: emergence of functional and dysfunctional empowerment. J Med Internet Res. 2017; 19(3):1-17 